\title{
A Note on a Framework to Assess the Required Equity Risk Premium Using Cumulative Prospect Theory
}

\author{
Chris Holdsworth ${ }^{1}$, Eben Maré ${ }^{2}$ \\ ${ }^{1}$ Investec Securities, Investec, Cape Town, South Africa \\ ${ }^{2}$ Department of Mathematics and Applied Mathematics, University of Pretoria, Pretoria, South Africa \\ Email: eben.mare@up.ac.za
}

Received December 11, 2013; revised January 11, 2014; accepted January 18, 2014

Copyright (C 2014 Chris Holdsworth, Eben Maré. This is an open access article distributed under the Creative Commons Attribution License, which permits unrestricted use, distribution, and reproduction in any medium, provided the original work is properly cited. In accordance of the Creative Commons Attribution License all Copyrights (C) 2014 are reserved for SCIRP and the owner of the intellectual property Chris Holdsworth, Eben Maré. All Copyright (C) 2014 are guarded by law and by SCIRP as a guardian.

\begin{abstract}
We provide a framework to ascertain the required equity risk premium (ERP) within the setting of Cumulative Prospect Theory (CPT) over arbitrary investment time periods. Once accounting for behavioral biases in estimating distributions (generated by using a simulation of asset returns based on a sampling procedure) and using a CPT utility function, it becomes apparent that the key determinant of the required ERP is an investor's time horizon.
\end{abstract}

\section{KEYWORDS}

\section{Cumulative Prospect Theory; Equity Risk Premium; Investment Time Horizon; Multi-Asset Allocation}

\section{Introduction}

The so-called equity risk premium (ERP) puzzle suggests that under the assumption of standard expected utility maximizing investors, the size of the equity risk premium would imply that investors would need implausibly large levels of risk aversion to hold any bonds at all, as shown by Mehra and Prescott [1].

Benartzi and Thaler [2] proposed a possible solution based on behavioral finance. One of the characteristics of Cumulative Prospect Theory (CPT) [3] is a kinked utility curve; investors are more sensitive to losses relative to a reference point than they are to gains. (See, also [4].)

However, given that the distribution of returns is linked to the time horizon over which returns are measured, the perceived utility of an investment would be linked to the frequency at which returns are observed, i.e., the time horizon of an investor. Given the observed ERP in the US equity market, Benartzi and Thaler [2] backed out an implied time horizon of roughly one year. Explicitly, if CPT is an accurate model of investor behavior, then a time horizon of one year would explain the observed historical equity risk premium.

We can apply a similar process to the South African market. Given the time horizon of investors, the current benchmark asset allocation and the distribution of asset class returns, one can use CPT to establish the required ERP to make an investor indifferent to a marginal investment in equity or bonds. In addition, by changing the assumed time horizon and benchmark allocation, it is possible to generate a sensitivity analysis to establish the assumptions required for each view of the ERP. This leaves generating the expected distribution of returns as the remaining uncertainty.

\section{Methodology and Results}

\subsection{Methodology}

In order to generate the distribution of returns for a given time horizon, we sampled the daily returns of the South African equity, bond, property and cash asset classes simultaneously and with replacement from July 1997 to December 2012. This allows us to simulate a distribution of annual returns, for example, using the historical marginal distributions and dependence structure rather than having to rely on an assumed multivariate distribution.

The forward looking distribution is, however, likely to be different from the historical distribution. This is clearly the case for bonds where the changing yield to 
maturity for long dated bonds provides evidence of at least one moment of the expected distribution of bonds changing over time. Unfortunately it is not as simple to estimate the change in the other moments for long time horizons.

Stott [5] and Booij et al. [6] provide reviews of the literature of probability weighting functions as well as their own estimates of the extent to which individuals overweigh extreme events.

Instead of weighting the probability density function (representing the probability of any specific return occurring), the weighting function is applied to the cumulative distribution function (CDF), (representing the probability of observing any return less than or equal to a specific return). We adjust the cumulative distribution function of returns using the following formula:

$$
w(p)=\frac{\delta p^{y}}{\delta p^{y}+(1-p)^{y}}
$$

where $p$ represents the empirical CDF.

We use the average of the empirical results in the literature to determine estimates for $\delta$ and $y$. This results in $\delta=0.73$ and $y=0.81$. This has the effect of shifting the CDF so that it takes on an inverse-s shape, implicitly giving greater weights to the tails in the underlying probability density function.

As an attempt at establishing the forward looking distribution of returns we shift the mean of the cash and bond distributions so that they equal the forward looking expected yield to maturity. We then determine the required ERP for an investor with a given time horizon and asset allocation to be indifferent between a marginal investment in equity or bonds using the CPT utility function after adjusting the CDFs using the formula above.

\subsection{Results}

The results of the calculation are shown in Table 1 indicating the required ERP (\%) for different time horizons (denoted in years) vs. different equity weights (\%).

\section{Conclusions and Observations}

The ERP does not accrue steadily over time. It has tended

Table 1. Required ERP.

\begin{tabular}{ccccccc}
\hline \multicolumn{7}{c}{ Equity weight (\%) } \\
\hline & 0.1 & 0.3 & 0.5 & 0.7 & 0.9 \\
Time & 1.0 & 1.1 & 2.8 & 3.8 & 4.2 & 4.5 \\
horizon & 3.0 & 0.3 & 1.5 & 2.4 & 2.8 & 3.0 \\
(Years) & 3.0 & 2.1 & 3.7 & 4.5 & 4.7 & 4.8 \\
& 5.0 & -0.3 & 0.5 & 1.3 & 1.9 & 2.1 \\
\hline
\end{tabular}

to arrive in spurts. Therefore, the tails of the distribution are important.

Once accounting for behavioral biases in estimating distributions and using a CPT utility function, it becomes apparent that the key determinant of the ERP is an investor's time horizon. The shorter the time horizon is, the greater the required ERP as a result of the sensitivity to losses is; and the shorter time period for available for the ERP accrual to occur is.

\section{REFERENCES}

[1] R. Mehra and E. C. Prescott, "The Equity Premium: A Puzzle,” Journal of Monetary Economics, Vol. 15, No. 2 1985, pp. 145-161. http://dx.doi.org/10.1016/0304-3932(85)90061-3

[2] S. Benartzi and R. H. Thaler, "Myopic Loss Aversion and the Equity Premium Puzzle," The Quarterly Journal of Economics, Vol. 110, No. 1, 1995, pp. 73-92. http://dx.doi.org/10.2307/2118511

[3] A. Tversky and D. Kahneman, "Advances in Prospect Theory: Cumulative Representation of Uncertainty," Journal of Risk and Uncertainty, Vol. 5, No. 4, 1992, pp. 297-323. http://dx.doi.org/10.1007/BF00122574

[4] D. Kahneman and A. Tversky, "Prospect Theory: An Analysis of Decision under Risk," Econometrica: Journal of the Econometric Society, Vol. 47, No. 2, 1979, pp. 263-291.

[5] H. Stott, "Cumulative Prospect Theory's Functional Menagerie,” Journal of Risk and Uncertainty, Vol. 32, No. 2, 2006, pp. 101-130. http://dx.doi.org/10.1007/s11166-006-8289-6

[6] A. Booij, B. van Praag and G. van de Kuilen, "A Parametric Analysis of Prospect Theory's Functionals for the General Population,” Theory and Decision, Vol. 68, No. 1-2, 2009, pp. 115-148. http://dx.doi.org/10.1007/s11238-009-9144-4 